\title{
Developing a Curriculum for Sino-Australia Cooperative Mechanical Engineering Program
}

\author{
Zhigang Jiang \\ National Demonstration Center for Experimental Mechanical Education, Wuhan \\ University of Science and Technology, \\ Wuhan 430081, China \\ Yanan Wang \\ Deakin University, Geelong, \\ Victoria 3216, Australia \\ Siva Chandrasekaran \\ Swinburne University of Technology, \\ Hawthorn 3122, Australia \\ Qiaoling Xiao \\ International School, Wuhan University of Science and Technology, \\ Wuhan 430081, China
}

\begin{abstract}
Guided by the purpose of fostering international high-quality engineering personnel, based on the problems found in a curriculum setup of Sino-Australian Mechanical Engineering collaborative teaching program. This study is focused on developing the curriculum setup that takes modern electro-mechanical product and system design as the principle, and develops students' fundamental, core and comprehensive employability as the centre, as well as achieves Sino-foreign mechanical engineering curriculum that includes target and contents, theoretical knowledge and practical projects, traditional classroom and online delivery, via research and practice from four aspects including course setup, practical component, teaching mode and assessment scheme, in order to provide theoretical and practical reference for a better Sinoforeign collaborative teaching model and reform of relevant teaching scheme. This paper discusses about the design and implementation of a Curriculum for Mechanical Engineering for the joint program. This Curriculum aims to educate the students, a multidisciplinary knowledge in the domain of Engineering, technology as well as management. The implementation of this curriculum at Wuhan University of Science and Technology has showed a large improvement of student skills that permits it to become a national curriculum.
\end{abstract}

Keywords: Sino-foreign collaboration; Mechanical Engineering Curriculum Setup; Engineering competency. 


\section{Introduction}

With the massive growth of the Chinese economy and fast development of higher education, Chinese-foreign cooperative education is regarded as an irresistible trend of the rapidly rising global education developing in China (Xiao and Zhang., 2017). The Sino-foreign cooperative education has grown rapidly in recent years, which provide a significant way to make full use of foreign educational resources, such as outstanding teacher resource, advance teaching style, studying abroad, and participating international programs for highly desirable skills (Jacobs., 1898). Along with this, the Australian universities have been hunting for international student diversification. Hence, many collaborative education programs between Australia Universities and Chinese universities have been carried out, including academic degree programs, exchange programs, summer programs and research programs. It is reported that there were more than 2400 Sino-foreign cooperative schools and programs with 30 countries of origin of the foreign partner universities by 2016 that have been approved by the Chinese Ministry of Education (MOE)(Daly et al.,2014).

In such background, the Wuhan University of Science and Technology (WUST) in China corporate with the Deakin University in Australia to implement an undergraduate collaborative program in Mechanical Engineering (approval number: MOE42AU2A20131394N) since 2013. Undergraduate students enrolled by the Department of Mechanical Engineering at WUST will have an opportunity to be transferred to Deakin University study after 2.5 years (5 semesters) study in China(Long et al., 2016). After that the students can choose to study Bachelor of Mechanical Engineering program for the 3rd and 4th year at Deakin in Australia. Upon successful completion of all the required units and meeting graduation requirements, students will receive a Bachelor of Mechanical Engineering (Honors) degree from Deakin(Chandrasekaran et al., 2013a). The students succeed in completing all courses at WUST and Deakin University will be awarded a Certificate of Graduation and a Bachelor's degree from WUST and Deakin.

There are several crucial characteristics of the cooperative program between Deakin and WUST. One of the important features is that the program focuses on a specific academic program, and both universities design the program together to cultivate students from WUST. Furthermore, students can utilize all the teaching resources at Deakin, and Deakin academics go to WUST to delivery courses. The credits obtained by the students can be recognized at each university(Chandrasekaran., 2014). In addition, WUST Mechanical Engineering staff members come to Deakin for professional development as teaching assistants. As an impact of this program, from the early stages six WUST students have transferred to Deakin in early 2015, and ten students were transferred to Deakin in 2016. The cooperative teaching program between Deakin and WUST has made a great achievement(Chandrasekaran et al., 2013b). However, the process of developing a cooperative teaching program depends on various factors such as the general educational policy of those countries, cultural issues, and the economic environments. Despite of all those benefits of cooperative teaching program, there are still some improvements of the 
curriculum need to be made to enhance Chinese student learning capability to an international standard. For example, there is a need for an organic integration of Sino-foreign courses. The cooperative curriculum consists of two parts, 16 courses are provided by Deakin and the rest of 24 courses are provided by WUST. These units are simply added together, lacking systematisms. Furthermore, the different teaching style and examination system between Chinese courses and foreign courses could also affect the joint program students.

Based on the background of the cooperative program, this research study is focused on curriculum development for teaching system construction practice in Sino-foreign cooperative teaching program. It explores how to combine Australian education organically with Chinese curriculum when it introduces foreign curriculum which provides a new learning and teaching approach through Sino-foreign cooperative international high-quality talent cultivation mode. The structure of this research paper can be summarized as follows: Section 2 describes the curriculum design and implementation of the cooperative curriculum between Deakin and WUST. In the next section, the implementation measures for cooperative curriculum, and the assessment plan and its results are presented in Section 3 and 4, respectively. Finally, conclusions and further improvements were presented. This research study analyses the student and staff experiences in the Sino-Australia cooperative teaching program. With the analysed results, this research study focuses on the curriculum development/restructuring of the undergraduate program in Mechanical engineering.

\section{Cooperative curriculum design and development}

The word curriculum is derived from the Latin currere meaning 'to run'. It provides a design or a structure which enables the learning in a study environment (Hadim et al.,2002). In terms of learning and teaching, curricula define a course or a program which describes the knowledge, skills and attributes for students to be acquired as learning outcomes.

The "Cooperative curriculum" is a new learning and teaching approach which rationally utilize high-quality education resources at home and abroad, also to realize internationalization of advanced education and to improve the talent of the Chinese students and enhance the learning and teaching cultivation quality(Lomas., 2007). The objectives of the co-operative curriculum course for Sino-Australia cooperative mechanical engineering program are stated as:

- Developing the students' ability to formulate and solve Mechanical Engineering Problems.

- Enhancing students learning capability to acquire skills as teamwork, organization skills, ethics, and critical analysis.

- Developing the relation between the department and the various industry partners as well as knowing the needs and expectations of these fields for graduating students.

- Improving the job opportunities for students' after graduation.

- Connecting students to the industrial environment and give them a glimpse on what their expecting career looks like. 
The students' knowledge is growing at the span of changing social-economic needs (Joordens., 2012). Academia requires a curriculum to meet the requirements of industry globally (Lang et al., 1999). Teachers should be active curriculum designers to explore and examine a curriculum design that applies to collaborative teaching approach (Trigwell et al.,1999). By understanding the growing need for curriculum integration programs around the world, the cooperative teaching program between Deakin and WUST brings reflective practitioners, international standard learning and teaching process for students internationally.

The cooperative curriculum is proposed to have a constructive effect on student theory knowledge and development of Mechanical Engineering graduates skills such as collaboration, critical thinking, innovation, creativity, and problem solving, which increase students intrinsic motivation and engage Mechanical Engineering graduates through new technology integration. Based on manufacturing industrial needs, an integrated curriculum model which integrates subjects, teaching and learning methods from both Universities (WUST and Deakin) has been developed, as shown in figure1.

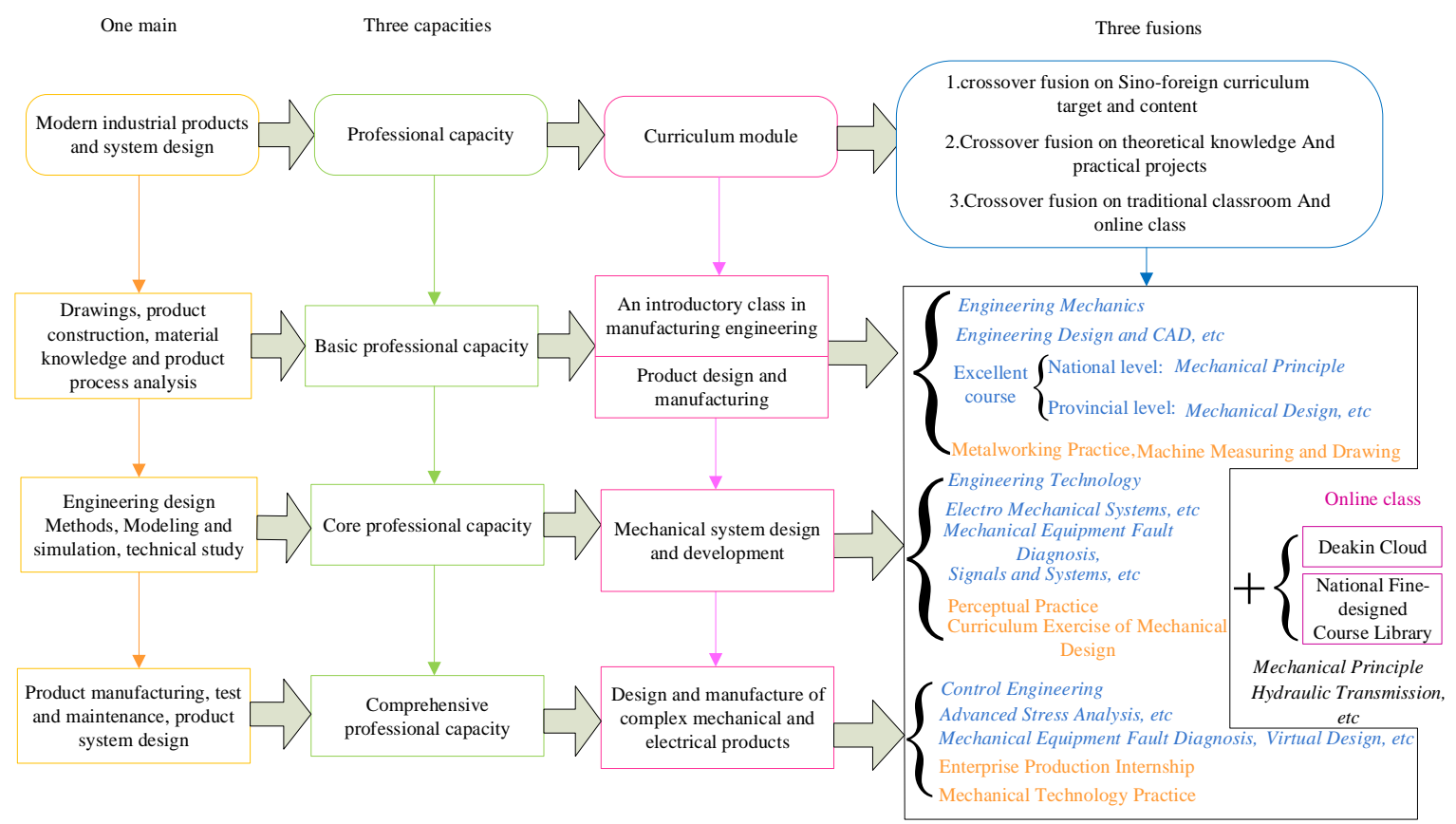

Figure 1: Flowchart of the developed curriculum for Sino-foreign Cooperative Mechanical Engineering Program.

There are four levels were detailed mainly for students which have been envisaged and stipulated, as shown is Table 1. The curricula have been presented, discussed and approved by stakeholders during a validation workshop in Year. Specifically, the four-curriculum modules have been developed to cultivate three profession capabilities for students from the joint program. 
Table 1 Course structure - Mechanical Engineering program

\begin{tabular}{|c|c|c|c|}
\hline \multirow{2}{*}{ Level 1} & Semester 1 & \multicolumn{2}{|l|}{ Mechanical Drawing A (I) } \\
\hline & Semester 2 & \multicolumn{2}{|l|}{ Mechanical Drawing A (II) } \\
\hline \multirow[t]{3}{*}{ Level 2} & Semester 1 & Engineering Mechanics & Engineering Materials \\
\hline & \multirow[t]{2}{*}{ Semester 2} & Strength of Materials & $\begin{array}{l}\text { Engineering Design and } \\
\text { CAD }\end{array}$ \\
\hline & & Fluid Mechanics & Finite Element Analysis \\
\hline \multirow[t]{6}{*}{ Level 3} & \multirow[t]{3}{*}{ Semester 1} & $\begin{array}{l}\text { Mechanical Engineering } \\
\text { Testing Technology }\end{array}$ & Manufacturing Technology \\
\hline & & Principles of Thermodynamics & Computer Aided Engineering \\
\hline & & Innovative Design of Machinery & \\
\hline & \multirow[t]{3}{*}{ Semester 2} & $\begin{array}{l}\text { Materials Selection and } \\
\text { Performance }\end{array}$ & Electro Mechanical Systems \\
\hline & & Dynamics of Machines & Mechanical Vibration \\
\hline & & $\begin{array}{l}\text { Fault Diagnosis for } \\
\text { Mechanical Equipment }\end{array}$ & \\
\hline \multirow[t]{2}{*}{ Level 4} & \multirow[t]{2}{*}{ Semester 1} & Advanced Stress Analysis & Control Engineering \\
\hline & & Metallurgical Machinery Design & $\begin{array}{l}\text { Metallurgical Equipment } \\
\text { Process and Equipment }\end{array}$ \\
\hline
\end{tabular}

The first level curriculum is designed for the freshmen, which includes the introductory courses in manufacturing engineering, such as "Mechanical Drawing", "Manufacturing Engineering Introduction", and "Metalworking Practice". This level focuses on cultivating the engineering cognitive ability and engineering thinking. In this period of study, the students tend to know the concepts, flows of engineering design, and have preliminary design ability (Sheppard and Jennison., 1997).

The second level is designed for the sophomore, concentrating on product design and manufacturing. This level module includes the courses, "Engineering Mechanics", "Engineering Design and Computer Aided Design", "Manufacturing Technology" et al. Through this period study, the students have the ability to design products and utilize the design tools and software.

The third level is provided for the junior, regarding mechanical system design and development. This level module includes the courses, "Mechanical Vibration", "Material Selection and Performance", "Manufacturing Technology" et al. Through this period study, the students have the ability to manufacture a product, and design a complex mechanical system.

The fourth level presented for the senior, considering the design and manufacturing of complex mechanical-electrical products. This level module includes the courses, "Electro-Mechanical System", "Mechanical Vibration", "Mechanical Innovation Design", etc., which focus on the comprehensive capability development of complicated mechanical and electrical products design and manufacturing, and the process management courses include complex products design and development flow and organization, interdisciplinary mission coordination design, process design. 


\section{Bring knowledge integration and engineering capacity development}

There are various learning and teaching approaches has been used in the mode of curriculum change or curriculum enhancement(Sander et al.,2000). The project based learning approach enhances students learning around projects to acquire product as an outcome. The problem based learning approach facilitates students to learn around problems through process as an outcome(Thomas et al., 2002). However, many university staff used traditional methods and practices in teaching. In this way, students are unable to link their skills with the professional learning curriculum. A gap exists between the learning expectations of students and the teaching approaches of staff (Grohman et al., 2013).

On the basis of the developed cooperative curriculum for the joint program between Wust and Deakin, it is necessary to propose an effective way to utilizing the teaching resources from both sides. Extending students' learning space from traditional curriculum approach to innovative teaching approach for both on-campus and off-campus students. Based on the Project-Oriented DesignBased Learning (PODBL) approach, Mechanical Engineering program teaches engineering mainly through design based project oriented semester-long projects, over the entire four years of the program (Yang., 2010).

Design based learning (DBL) is a combination of project based and problem based approaches. Project Oriented Design Based Learning (PODBL) is defined as facilitating students with design activities around projects in studio based learning environment(Blumenfeld et al.,2016). Teaching is through small or big projects; students work in teams with combinations of off-campus and oncampus students. Integration of technology resources in DBL takes place within these groups through collaborative learning and active learning (Barell., 2006).

The project-oriented design based learning approach (PODBL) is a learning and teaching model where students learn through projects around design-focused activities that involve studio based learning environment at Deakin. In order to implement PODBL, Wust also constructs a multi-dimensional and "full process and multiple dimensions" curriculum practice system. Its multi-dimensional features are curriculum practice, innovation practice and social practice outside classroom.

During the few years of cooperative teaching program, the curriculum is implemented with around 72 students per year. Many interesting insights were pointed out. It has been noticed that the skills of the students have been raised significantly, especially in the mechanical design side and "industrial thinking"; this term means that students, thanks to the repeated industrial training that are considered very important by the faculty staff, became to think with more pragmatic ways to solve problems, and not by the traditional way (mathematical problem solving). 
Students are asked in almost all courses to make (in teams of 4 or more students) mini projects that they have to present in class. This mini project presentations had a tremendous effect on their skill of communication as well as team work (in addition to the knowledge acquired during the project work), as shown in Figure 2. In addition, one of the team attended the "seventh National Innovation Design Competition", and obtained a Gold Award, as shown in Figure 3. Bachelor senior project is also performed in multidisciplinary teams (from all minors), the aim being to encourage students to work with people, having different skill, helping each other's. Finally, a rate of success increases by $50 \%$ was noticed as compared to other similar curriculum in our university.

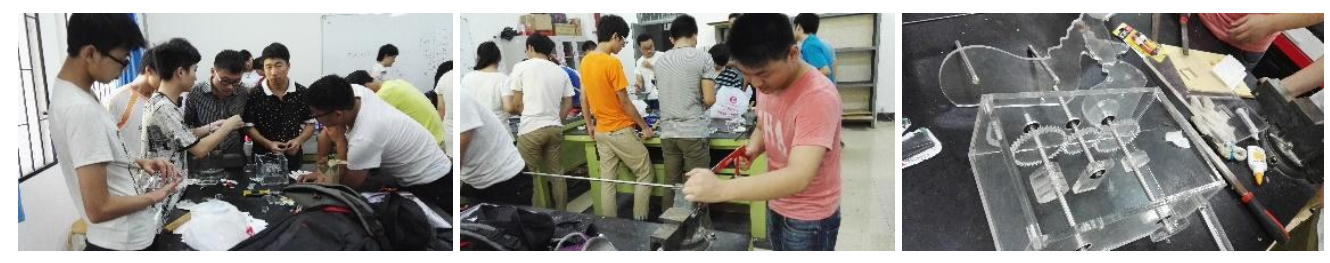

Figure 2 The product design and manufacturing process
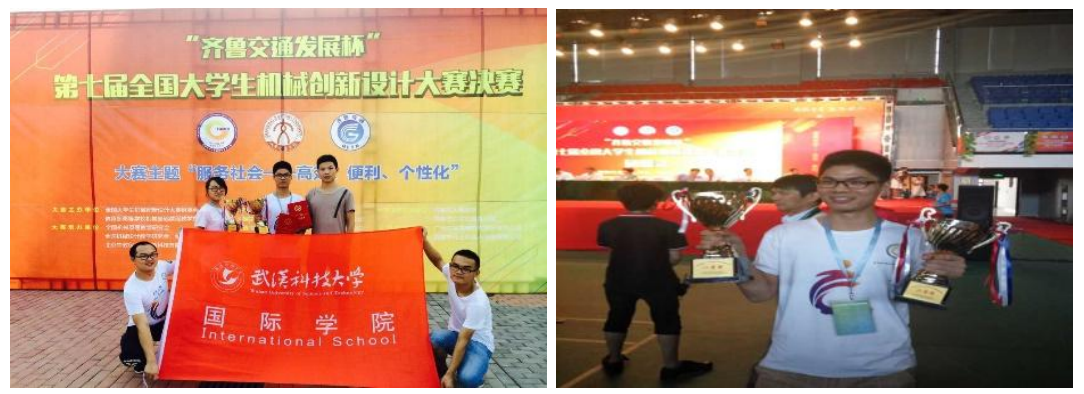

Figure 3 Gold Award in the "seventh National Innovation Design Competition"

\section{Results and analysis}

In order to assess the collaborative teaching program between WUST and Deakin, a qualitative and quantitative paper-based survey was utilized to obtain student perspectives on the curriculum and teaching system. Qualitative methods are useful for evaluating Sino-Australia cooperative program goals and for involving participants in the assessment process to know their insight and perspective. The quantitative and qualitative surveys were conducted with more than 180 WUST students, 160 students responded to the survey and surveys were conducted with 8 Deakin staff who visited WUST for teaching Mechanical engineering units in collaboration with respective WUST academics.

The quality of the current cooperative program is analysed by evaluating WUST students' perceptions and experiences during last two years of study program. The students respond to survey questions Q1(What was the main reason when you applied to joint program at WUST? ) and Q2 (Does the collaborative curriculum between WUST and Deakin meet your expectations?), and the analysed results are shown in Figure 4. 


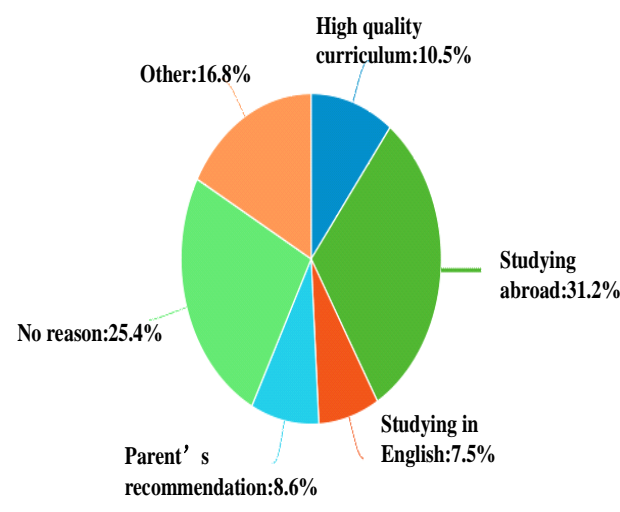

(a) results of Q1

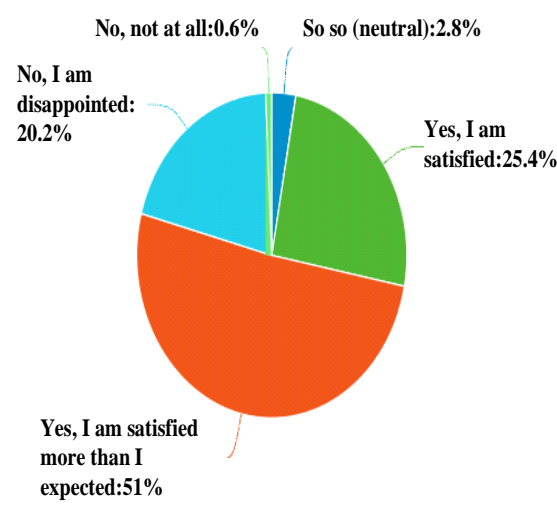

(b) results of Q2

Figure 4 Joint Program Quality Assessment

Figure 4 shows the analysed results on the Quality Assessment of program. When the students were asked about the primary reason to apply at joint program, WUST. Figure 4(a) clearly shows that $49.2 \%$ of students were selected international partnership education program at WUST, due to various academic interest exploring on study abroad (31.2\%), curriculum (10.5\%), and communication skills (7.5\%). On the other hand, when the students were asked about their expectations were met by the cooperative teaching program, about $51 \%$ says satisfied than expected, about $25.4 \%$ says basic satisfied and around $20.2 \%$ of students responded being undesirable about the cooperative teaching program (see Figure $4(b)$ ). The analysed results show that overall collaborative teaching program appeals the students' need and their satisfaction are positive.

The survey affirms that most of the students in the joint program had a quality learning experience through collaborative teaching. They expressed that the new collaborative curriculum and teaching motivates to learn and the practical activity enhanced their learning compared to traditional learning. Moreover, the project/design-based learning activities have enhanced students learning capability of understanding practical/theoretical prospects in this course. In addition, some of the students mentioned that communication plays an important role towards teaching and understanding of the subject when it is being taught in a second language by the academics from Deakin. Our future work will focus on greater cooperation between Chinese and Australian instructors to ensure the best possible learning experience.

\section{Conclusion}

In this research study, the cooperative teaching program team presented a new curriculum for Bachelor degree in Mechanical Engineering. The curriculum is enhanced with engineering and technology courses that permit the future engineers to have multidisciplinary skills. The aim is to help small companies to hire high level engineers that can fit the different domain of knowledge needed for their development. Students found the curriculum very attractive. The students interest in studies increased and consequently the possibility of success also grows. The implementation of this curriculum at WUST has showed a large 
improvement of student skills which permits it to become a national curriculum. However, there are several issues in the cooperative teaching program that should be addressed for better quality, such as English language issue, advanced teaching staff and facilities.

\section{Acknowledgements}

This work described in this paper was sponsored by Hubei Provincial Department of Education of China (2015224) and Wuhan University of Science and Technology (Yjg201413). All contributions to this work are gratefully acknowledged.

\section{References}

Barell, J. (2006). Problem-based learning: an inquiry approach. Thousand Oaks, CA: Corwin Press.

Blumenfeld, C.P., Soloway, E., Marx, R.W., Krajcik, S. J., Guzdial, M \& Palincsar, A. (2016). Motivating project-based learning: sustaining the doing, supporting the learning. Educational Psychologist, 26(3-4), 369-398. https://doi.org/10.1207/s15326985ep2603\&4_8

Long, J. M., Chandrasekaran, S., Wang, Y.N., Nomani, J., Zhao, Q., Jiang, Z.G., Geng, D.L., \& Rolfe, B. (2016). Australasian partnership in a first-year engineering course: Deakin University and Wuhan University of Science and Technology. in ASEE 2016. Proceedings of the American Society for Engineering Education International Forum. American Society for Engineering Education (ASEE) .

Chandrasekaran, S., Stojcevski, A., Littlefair, G., \& Joordens, M. (2013a).Accreditation inspired project oriented design based learning curriculum for engineering education. in IETEC 2013. University of Technical Education, Ho Chi Minh City.

Chandrasekaran, S., Stojcevski,A., Littlefair, G., \& Joordens, M. (2013b). Project-oriented design-based learning: aligning students' views with industry needs. International Journal of Engineering Education, 29(5), 1109-1118.

Chandrasekaran, S. (2014). Cloud-linked and campus-linked students' perceptions of collaborative learning and design based learning in engineering. International Journal of Digital Information \& Wireless Communications, 4(3),267-275. https://doi.org/10.17781/p001275

Daly, S. R., Mosyjowski, E. A., \& Seifert, C. M. (2014). Teaching creativity in engineering courses. Journal of Engineering Education, 103(3),417-449. https:// doi.org/10.1002/jee.20048

Guskey, R.T. (2002). Professional development and teacher change. Teachers \& Teaching, 8(3), 381-391. https://doi.org/10.1080/135406002100000512

Grohman, M. G., \& Szmidt, K. J. (2013). Teaching for Creativity: How to Shape Creative Attitudes in Teachers and in Students. Teaching Creatively and Teaching Creativity. Springer New York. https://doi.org/10.1007/978-1-4614-5185-3_2

Hadim, H. A., \& Esche, S. K. (2002). Enhancing the engineering curriculum through project-based learning. Frontiers in Education, IEEE.

Lang, J. D., Cruse, S., Mcvey, F. D., \& Mcmasters, J. (1999). Industry expectations of new engineers: a survey to assist curriculum designers. Journal of Engineering Education, 88(1), 43-51.https://doi.org/10.1002/j.2168-9830.1999.tb00410.x

Lomas, L. (2007). Are students customers? perceptions of academic staff. Quality in Higher Education, 13(1), 31-44. https:/ / doi.org/10.1080/13538320701272714

Ituma, A. (2011). An evaluation of students' perceptions and engagement with e-learning components in a campus based university. Active Learning in Higher Education, 12(1), 57-68. https:// doi.org/10.1177/1469787410387722 
Jacobs, H. H. E. (1989). Interdisciplinary curriculum: design and implementation. Association for Supervision \& Curriculum Development Cited in T, 99.

Joordens, M., Chandrasekaran, S., Stojcevski, A., \& Littlefair, G. (2012). The process of design based learning: A students' perspective. Profession of Engineering Education: Advancing Teaching, Research and Careers:, Conference of the Australasian Association for Engineering Education (pp.927).

Sander, P., Stevenson, K., King, M., \& Coates, D. (2000). University students' expectations of teaching. Studies in Higher Education, 25(3), 309-323.

Sheppard, S. \& Jennison, R.(1997). Freshman engineering design experiences and organizational framework. International Journal of Engineering Education., 13, 190-197.

Trigwell, K., Prosser, M., \& Waterhouse, F. (1999). Relations between teachers' approaches to teaching and students' approaches to learning. Higher Education, $37(1), 57-70$.

Xiao, H. \& Zhang, X. (2017). Assuring Quality in Transnational Higher Education: A Case Study of Sino-Foreign Cooperation University in China. Quality Assurance in Asia-Pacific Universities, Springer. 55-69. https:// doi.org/10.1007/978-3-31946109-0_4

Yang, N. B. (2010). Applying Project-Based Learning to Product Design Teaching. International Conference on System Science, Engineering Design and Manufacturing Informatization. IEEE, 171-173.

https://doi.org/10.1109/icsem.2010.52 